\title{
IMIGRAÇÃO, PRECONCEITOS E OS ENUNCIADOS SUBJETIVOS DOS ETNOCENTRISMOS
}

Giralda Seyferth *

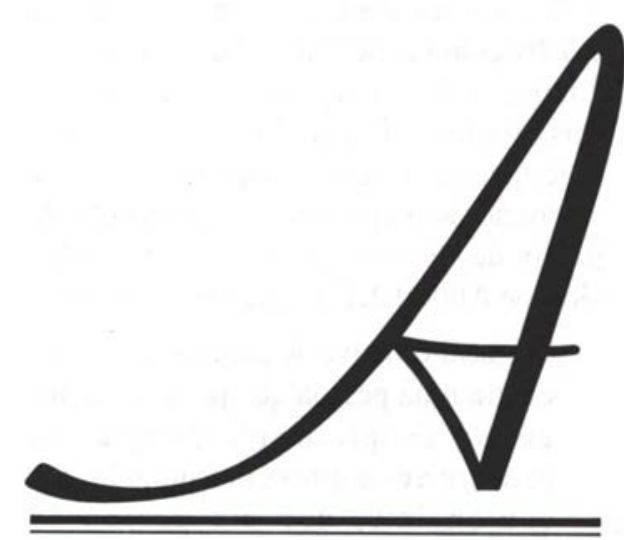

colonização de várias regiões do sul do Brasil por imigrantes europeus começou em 1824, com a fundação da colônia de São Leopoldo (RS) por alemães, numa iniciativa do governo imperial visando o povoamento de um território ainda sujeito às disputas fronteiriças, $\mathrm{e} o$ desenvolvimento de uma forma de exploração agrícola distinta da grande propriedade escravista. A proibição da presença de escravos no regime de colonização só ocorreu no final da década de 1840 quando, de fato, houve a retomada do fluxo imigratório (alemão), interrompido desde $1830^{1}$. A intensificação do processo de colonização ocorreu após a promulgação da lei 601 - a Lei das Terras - em 1850, que influenciou a política imigratória associando-a ao desenvolvimento de um sistema agrícola baseado na pequena propriedade familiar. Desde então, imigrantes europeus de diversas procedências, com predominância de alemães, italianos e poloneses, na condição de colonos, receberam terras destinadas à agricultura demarcadas em "linhas coloniais", povoando uma parte substantiva da região sul na forma que Jean Roche (1969) denominou "enxamagem" uma evocação da multiplicação de colmeias, metáfora para assinalar a expansão dos núcleos coloniais.

Vários fatores, contidos na legislação após 1850 , contribuíram para a ampliação e desenvolvimento dessa forma de ocupação territorial: parte das terras devolutas passou para o controle dos governos provinciais encarregados de promover a imigração; o acesso à propriedade do lote colonial só podia ocorrer por compra (acabando, portanto, a gratuidade da concessão); aos poucos o governo imperial voltou a conceder subsídios (basicamente, passagens de navio e pagamento parcelado do lote); foi autorizada a formação de empresas particulares de colonização, que passaram a receber grandes concessões de terras públicas para promover o assentamento (na época denominado "localização") de colonos - as duas mais importantes "colônias alemãs" de Santa Catarina (Blumenau e Joinville) surgiram desse tipo de iniciativa. A noção de "enxamagem" mostra a constância com que, durante mais de cem anos, imigrantes e descendentes se espalharam pelo Rio Grande do Sul, Santa Catarina e Paraná, formando um campesinato com características diversas do brasileiro.

Dois aspectos são significativos nesse processo: a ocupação ocorreu, 
principalmente, em terras públicas, em grande parte cobertas por florestas, formando "zonas pioneiras", conforme Waibel (1958); a noção de terra pública ou devoluta não levou em conta a possível presença de posseiros em algumas áreas destinadas à colonização com imigrantes, fato que aponta para a exclusão dos "nacionais" indicada, inclusive, na legislação republicana. A exclusão é reflexo seguro dos preconceitos raciais vigentes, inclusive no aparelho de Estado, desde meados do século XIX, e que recrudesceram no alvorecer da República com a tese do branqueamento vinculada à imigração européia. No discurso das elites (inclusive da área acadêmica), quando se trata da imigração, o brasileiro comum, mestiço, índio ou negro, foi condenado à inferioridade racial, apesar da mestiçagem ter sido imaginada enquanto processo depurador da produção de um povo branco com o concurso do imigrante. Por isso houve tanto debate sobre a inconveniência das correntes migratórias oriundas da Ásia e da África ${ }^{2}$. Nesse sentido, é paradoxal que a política de colonização tenha privilegiado a concentração de imigrantes em certas áreas, motivo de crítica dos ideólogos do branqueamento em busca da unidade e homogeneidade racial e cultural da nação, e que clamavam pela distribuição eqüitativa de estrangeiros brancos no território nacional (conforme Romero, 1902, por exemplo).

Enfim, a colonização e a imigração produziram diferenças sociais e culturais no meio propriamente rural, nas cidades emergentes de núcleos coloniais e nas cidades de Porto Alegre, Rio Grande, Curitiba, etc., onde também se estabeleceram imigrantes e egressos do sistema colonial. As peculiaridades das chamadas zonas coloniais italianas, alemãs, polonesas - formando culturas híbridas, conforme expressão de Willems (1980) - serviram para marcar pertencimentos, identidades culturais próprias dos sistemas interétnicos. Em grande parte, tais pertencimentos também foram externalizados - especialmente antes de 1937 - através de publicações, monumentos, associações culturais e recreativas, ganhando maior visibilidade e motivando reações nacionalistas que culminaram na campanha de nacionalização do Estado Novo (19371945). Entre os diferentes grupos de imigrantes e descendentes, e entre estes e os brasileiros, manifestaram-se as subjetividades próprias da xenofobia, do preconceito (inclusive racial) e do etnocentrismo marcador das identidades coletivas contrastando com os princípios da nacionalidade brasileira igualmente carregados de preconceito contra aqueles cidadãos considerados alienígenas. Estas manifestações são o objeto do presente trabalho, tendo em vista a noção de preconceito e seus correlatos etnocentrismo e discriminação.

\section{UMA SÍNTESE DOS ENUNCIADOS CONCEITUAIS}

O termo preconceito, em geral, é usado no seu significado dicionarizado mais imediato: "conceito ou opinião formados antecipadamente, sem maior ponderação ou conhecimento dos fatos; idéia preconcebida" (Aurélio Buarque de Holanda Ferreira, Novo Dicionário da Língua Portuguesa, 1975: 1127). O verbete contém outros elementos de definição, apontando aos termos relacionados - "julgamento ou opinião formada sem se levar em conta o fato que os conteste; prejuízo ... superstição, crendice, ... suspeita, intolerância, ódio irracional ou aversão a outras raças, credos, religiões ..." (idem). Outros dicionários têm enunciados semelhantes, também presentes no senso comum ${ }^{3}$.

Apesar das dificuldades, desde a década de 1940 houve um estorço no campo das Ciências Sociais e, principalmente, da Psicologia, no sentido de construir um conceito viável como instrumento analítico para o estudo das relações entre grupos minoritários (ou minorias) e maioria em contextos nacionais, sobretudo nos Estados Unidos. Ao definir "minoria", Wirth (1945) referiuse às marcas físicas ou culturais em geral usadas para distinguir e tratar diferencialmente grupos de pessoas coletivamente discriminadas. Nesse sentido, maioria e minoria são termos que não possuem conteúdo estatístico; são relacionais e apontam para desigualdades sociais e políticas. Ou, na acepção de Eriksen (1993: 121), minoria é uma noção aplicada a grupos étnicos que não são hegemônicos no Estado onde vivem. A noção da cidadania, muitas vezes, é imaginada incompatível com a diversidade étnica, especialmente em Estados com políticas assimilacionistas; por outro lado, a mesma idéia de incompatibilidade pode produzir práticas segregacionistas. Max Weber chamou a atenção para a dimensão política das relações raciais nos Estados Unidos, referindo-se ao desprezo ou repulsa em relação aos negros como construções sociais que desqualificam socialmente (Weber, 1991: 267) -entendimento também presente em Wirth. A variável ali destacada, mais tarde, foi chamada de preconceito/discriminação.

As definições surgidas na década de 1950 estão na interface entre a Sociologia e a Psicologia Social, relacionadas aos domínios das relações intergrupais. A forma mais direta da definição de preconceito é aquela que o considera sinônimo de prejulgamento infundado. A partir desse princípio, por exemplo, Gordon Allport definiu preconceito como:

"Uma alternativa de evitação ou hostil contra uma pessoa que pertence a um grupo, simplesmente porque ela pertence a esse grupo, presumindo, por conseguinte, que ela possua as qualidades censuráveis atribuídas ao grupo" (Allport, 1958: 8).

Destaca-se, aí, o fato de que o preconceito, no cotidiano, é quase sempre um assunto da conduta individual, mas também concerne a um grupo como um todo. Allport está falando de preconceito étnico (incluindo a variável raça), "antipatia baseada numa generalização falha e inflexível”. A proposição conceitual do autor (que, afinal, realiza uma alentada análise da "síndrome do preconceito" na sua dimensão étnica e enquanto "problema psicológico") inclui, além das atitudes e crenças generalizadas e errôneas, os "graus" da ação que vão desde a expressão verbal (locução) dos antagonismos, até o extermínio (linchamento, massacre, 
genocídio, passando pela evitação, discriminação/segregação e ataque físico (Allport, 1958: 14-15).

Allport considerou o preconceito um "tipo de categorização" que predispõe os indivíduos a construir prejulgamentos injustificados - parte dos valores pessoais, concepção que direcionou a maior parte dos estudos para os temas da personalidade preconceituosa e dos conflitos intergrupais. O trabalho de Simpson e Yinger (1965), apesar da abordagem sociológica das "situações maioria-minoria", por exemplo, tem orientação semelhante, ao definir preconceito como "atitude emocional e rígida", "predisposição para responder a um certo estímulo" em relação a um grupo de pessoas. Nesta definição preconceitos são considerados atitudes com uma qualidade emocional, que supõem a seleção e ênfase de alguns fatos e a supressão de outros. E mesmo as novas experiências são direcionadas para velhas categorias, portanto, preconceito envolve não apenas prejulgamento mas, igualmente, um julgamento incorreto ou injusto dos membros de um dado grupo humano, uma ação orientada socialmente (Simpson e Yinger, 1965: 9-13). Outros dois pontos são assinalados por estes autores: a relação entre preconceito e discriminação e a importância do pensamento estereotipado na formação do preconceito. Preconceito é uma atitude, uma resposta simbólica e não envolve, necessariamente, uma ação aberta; um indivíduo pode ter preconceito contra um grupo minoritário que sequer conhece; por isso, não deve ser equacionado com discriminação (ou o tratamento categórico e diferencial de indivíduos e grupos que não são considerados em conformidade com os códigos institucionalizados). Enfim, discriminação é a "expressão aberta do preconceito". E a estereotipia, por seu alto grau de rigidez e sua pouca ou nenhuma relação com os fatos, ajuda a conformar os preconceitos.

Estes enunciados conceituais estão referidos, principalmente, à dimensão interétnica e não envolvem uma concepção geral de minoria ou grupo minoritário. Conforme observação de Klineberg (1972), trata-se de prejulgamento injustificado e discriminação de grupos que se distinguem por características físicas e/ ou diferenças culturais. Daí a importância atribuída aos conceitos de estereótipo e etnocentrismo.

O termo estereótipo é bastante usado, mas raramente tem sido objeto de uma discussão conceitual. Os dicionários, em geral, dão ênfase ao seu conteúdo tecnológico - a duplicata de uma superfície de impressão. Ou, mais precisamente, o processo pelo qual um tipo é fundido num molde ou placa de metal chamada estereótipo. A analogia sociológica é perfeita pois, como observou Harding (1972) estereotipar (em tipografia) é produzir uma superfície de impressão que pode ser usada em milhares de outras; e o adjetivo estereotipo exprime algo "mecanicamente repetido". Este é, precisamente o significado do termo: imagem padronizada, banalizada, resistente a modificações. $\mathrm{O}$ estereótipo compõe-se de um conjunto de características usadas para tornar típico um grupo, fazendo generalizações representadas de forma caricaturesca e inflexível. Tem a peculiaridade da simplificação e, segundo Preiswerk e Perrot (1975: 237), ela procede "de uma escolha limitada de elementos específicos, de omissões conscientes e de simples esquecimentos"; engloba as unidades da categoria que pretende cercar em uns poucos traços ${ }^{4}$.

As ponderações sobre os termos preconceito e estereótipo apontam à complementariedade dos seus enunciados e, principalmente, a grande abrangência que não se restringe às relações entre grupos etnicamente diferenciados. Assim, no importante trabalho sobre facismo e antisemitismo de Adorno e colaboradores (The authoritarian personality, $1^{\text {a }}$ edição 1950), apesar da sua definição como um estudo sobre preconceito, este termo foi considerado pouco adequado por causa dos seus numerosos significados e conotações. Nesse caso, preconceito (étnico) ficou englobado no conceito de etnocentrismo:

"Preconceito é comumente considerado um sentimento de aversão contra um grupo específico; etnocentrismo, por outro lado, refere-se a um arcabouço mental relativamente consistente e concernente aos alienígenas em geral" (Levinson, 1969: 102).

Embora o entendimento do etnocentrismo seja ancorado à definição sociológica original de W. G. Sumner Levinson, autor do capítulo sobre a ideologia etnocêntrica na obra coletiva encabeçada por Adorno, o enuncia como a tendência ao centralismo étnico, a rigidez na aceitação daqueles que são culturalmente iguais e a rejeição dos diferentes - o uso do conceito, no caso em questão, está restrito aos aspectos psicológicos das relações entre grupos distintos, às atitudes que os indivíduos têm em relação ao seu grupo e aos outros, como tais idéias se desenvolvem, e de que forma interferem na personalidade.

Interessa, aqui, reter o significado deste termo na Antropologia, tendo em vista a questão das diferenças culturais articuladas à construção simbólica das identidades étnicas, e o postulado da sua universalidade. A maioria dos autores que trataram do tema se reportam a uma obra de Sumner (intitulada Folkways, publicada em 1907), onde etnocentrismo é considerado aquele ponto de vista segundo o qual nosso próprio grupo é o centro de tudo, e todos os outros são avaliados por referência a ele ${ }^{5}$. Nesse caso, o etnocentrismo supõe um princípio de pertencimento positivo culturalmente configurado em contraposição a outros grupos, com culturas diversas, muitas vezes socialmente desqualificados.

Wagley e Harris (1958), por exemplo, observaram que o etnocentrismo é uma característica estrutural das relações (conflituosas) maioria - minoria, exatamente porque indica a crença de que os próprios costumes, linguagem, características físicas, etc., são melhores ou mais "naturais" do que as dos outros. Para o indivíduo ou grupo etnocêntrico os outsiders (os que estão fora) são apenas quase humanos. $\mathrm{E}$, acresentam:

“... a tendência universal de considerar nossa própria cultura e tipo racial superior leva ao aparecimento de difernetes formas de etnocentrismo ..." (Wagley e Harris, 1958: 259).

Essa "tendência universal" faz parte do conceito desde o primeiro enunciado 
de Sumner. Mas, de acordo com Preiswerk e Perrot (1975: 58), é fenômeno universal apenas em nível coletivo pois nem todos os indivíduos aceitam, integralmente, os valores do seu grupo. Valores etnocêntricos, portanto, conformam pertencimentos grupais em diferentes níveis - grupos étnicos, minorias, nacionalidades, ou mesmo nos movimentos de unificação preconizados por frações das elites (caso, por exemplo, do pangermanismo), ou nos regionalismos (Preiswerk e Perrot, 1975).

A diversidade das culturas, nos diz Levi-Strauss:

"Raramente se apresentou aos homens tal como ela é: um fenômeno natural, resultante das relações diretas ou indiretas entre as sociedades; eles viram nela antes uma espécie de monstruosidade ou de escândalo..." (Levi-Strauss, 1970: 236).

Aí, etnocentrismo é o repúdio puro e simples das formas culturais distintas das nossas, a recusa do próprio fato da diversidade cultural. Levi-Strauss estava se referindo à desqualificação daqueles que o ocidente chamou de bárbaros e selvagens, mas também mostra um paradoxo pois a "atitude de pensamento" que rejeita a humanidade dos chamados "selvagens" é também a atitude marcante e distinta desses mesmos selvagens. Ruth Benedict fez observação semelhante, reafirmada por Wagley e Harris (1958: 258).

A breve menção a esses conceitos, de certa forma, aponta para as dificuldades da aceitação igualitária da diversidade cultural e das distinções de natureza biológica subsumidas na idéia de raça, implícitas nas noções de minoria e grupo étnico. Preconceitos e etnocentrismo marcam tanto os princípios da nacionalidade quanto as etnicidades - um fato que não deve obscurecer a subordinação social e/ou política dos chamados grupos minoritários (nacionais ou étnicos).

A imigração costuma produzir uma pluralidade cultural conflitante com o nacionalismo dominante - identidades culturais cuja forma discursiva remete às fronteiras (sociais) intergrupais. Nos domínios das etnicidades e do nacionalismo, e tendo em vista o processo de colonização estrangeira no sul do Brasil, configuram-se retóricas etnocêntricas que procuram distinguir, subjetivamente, grupos de imigrantes e nacionais.

\section{A IDENTIDADE NACIONAL E OS ALIENÍGENAS}

As primeiras imagens estereotipadas sobre imigrantes aparecem em meados do século XIX, quando o governo imperial brasileiro voltou a incentivar o agenciamento de colonos europeus. Vários escritos da elite imigrantista - isto é, aquele segmento da classe dominante interessado num modelo de agricultura baseada no trabalho livre - mostram as preferências nessa ou naquela nacionalidade, com enumeração dos desejáveis e dos indesejáveis. Por outro lado, a categorização de imigrantes contida na legislação também não escapou dessa forma de contingenciamento (Seyferth, 2002a). Assim, a "moralidade" e a suposta propensão ao trabalho agrícola independente são "qualidades" atribuídas aos alemães e negadas, por exemplo, aos irlandeses chamados de escória, vagabundos, aventureiros, desordeiros e outras adjetivações desabonadoras que constam da documentação oficial de administradores de colônias da província de Santa Catarina (Seyferth, 1999). Esse modo de categorização tem relação direta com o fracasso da "colônia irlandesa" localizada no Vale do Itajaí e, igualmente, reflete o preconceito de europeus e norteamericanos em relação a um povo "periférico" considerado rústico e pouco civilizado - bárbaros na Europa moderna.

Nas hierarquias, os imigrantes ideais precisavam ser colonos ideais, supondo o amor pelo trabalho agrícola e todo um conjunto de qualidades vinculada à condição camponesa. São arrolados estereótipos positivos, conforme o relatório do Conselheiro Menezes e Souza apresentado ao Ministério da Agricultura, Comércio e Obras Públicas e publicado em 1875. Alemães, belgas, suíços, espanhóis e portugueses são considerados bons para colonizar; os italianos não teriam essa propensão. O autor recorre a outras opiniões para afirmar que os alemães amam o trabalho, são pacientes, corajosos, perseverantes; os belgas aparecem como "trabalhadores agrícolas moralizados e inteligentes"; os suíços, apesar de dedicados à relojoaria, pastoreio e confeitaria, pela "ductilidade" facilmente tornam-se excelentes lavradores; os espanhóis são sóbrios, laboriosos, humildes e os portugueses são infatigáveis, resistentes ao sol como o mestiço e o nacional (Menezes e Souza, 1875: 403411). Estão aí valorizadas certas qualidades morais que, aparentemente, deviam garantir a boa colonização e, sobretudo, o bom comportamento dos imigrantes. Mas é bom lembrar que o referido autor (como outros dos seus contemporâneos) está falando de europeus - isto é, da imigração branca. $\mathrm{O}$ discurso muda para a questão racial quando o assunto é a imigração asiática. Entram em cena os estereótipos negativos - a desqualificação social e os estigmas da raça: "indianos" e "chins" (ou coolis) recebem a classificação de membros de sociedades envelhecidas e decréptas, destituídas do espírito de progresso, raças abastardadas, feias, pouco industriosas. A aversão aos chineses reflete o símbolo da decadência civilizatória representada pelo ópio; nos termos de Menezes e Souza essa imigração traz consigo torpeza, devassidão, imoralidade, corrupção, degeneração moral e física. E, mencionando as "memórias do Dr. Nicolau Joaquim Moreira”, afirma:

“... a colonização chinesa será para nós um transbordamento de flagelos, porque nos virá abastardar a raça, inocular-nos o vírus da imoralidade, por um cravo na roda do progresso agrícola ..." (Menezes e Souza, 1875: 418).

Raça não é um problema quando se trata de europeus; é bem diferente no caso dos orientais pois aí emerge o problema da miscigenação. Nesse período - década de 1870 - em plena vigência do regime escravista, nada é dito sobre uma possível imigração africana. Ou melhor, ela é descartada porque significaria "o indireto 
restabelecimento do tráfico" (Menezes e Souza 1875: 423).

Essa categorização estereotipada e, no caso dos orientais e africanos refletindo preconceitos raciais, aparece sob outras formas em autores de retórica mais cuidadosa - caso de Tavares Bastos, por exemplo, que (em 1867) preferia a imigração de farmers - fazendeiros brancos do sul dos Estados Unidos descontentes com os rumos da guerra civil, denominados "lavradores inteligentes e ousados" (Tavares Bastos, 1976: 62). Não se posicionou contra a "importação" de chineses e indianos, numa pequena discordância com alguns dos seus contemporâneos paulistas. No entanto, tal recrutamento de trabalhadores asiáticos devia ficar para a iniciativa privada pois, era gente "de vícios e defeitos geralmente conhecidos" e ao governo competia apoiar (com subsídios) a formação de correntes migratórias dos povos civilizados (Tavares Bastos, 1976: 90). O significado disso é simples: os asiáticos não eram pensados como imigrantes; sua condição só podia ser a de trabalhadores temporários para solucionar a demanda de mão-de-obra.

Classificações semelhantes estão presente na legislação e não desaparecem depois de 1889. Na República, o problema da miscigenação vinculado à assimilação dos alienígenas suscitou numerosas discussões no âmbito da política imigratória, refletindo maior influência das teorias raciais, particularmente aquelas surgidas com a rubrica da eugenia. Raça, imigração e progresso eram termos associados; a crença na superioridade racial dos brancos continuou produzindo a desqualificação biológica e cultural de asiáticos e negros e, às vezes, dos chamados "povos semíticos" (incluindo árabes e judeus). Comparando o citado trabalho de Menezes e Souza com o de Joaquim da Silva Rocha (1918) - outro relatório produzido por alto funcionário do Ministério da Agricultura ${ }^{6}$ - observamos os mesmos critérios estereotipados, ditos da mesma maneira e com o intuito de qualificar o imigrante europeu idealizado, apesar de passados mais de quarenta anos e da crítica republicana ao modelo de colonização estrangeira do Império, afinal mantido sem grandes alterações. Por outro lado, aparecem os mesmos preconceitos contra os asiáticos, agora abarcando também os japoneses que, desde 1908 estavam chegando ao Brasil debaixo de protestos de boa parte dos pensadores nacionalistas afinados com a tese do branqueamento dos brasileiros. O preconceito é, mais uma vez, manifestado na forma de estigma da decadência/ decrepitude/bastardia/física e cultural, particularmente em relação aos chineses; já os japoneses entraram na categoria de suspeitos de intenções expansionistas.

Na hierarquia de J. da Silva Rocha (1918: 70-76) o elemento discordante é a desqualificação dos alemães, cujo "valor produtivo" sucumbe à "dificuldade de assimilação às raças latinas", passando assim de colono ideal privilegiado pela política de colonização do Império a alienígena irredutível. O ideal de assimilação estava presente no discurso sobre a imigração no Império e produziu conflitos especialmente com os alemães. Afinal, a religião evangélica luterana professada por parcela significativa desses imigrantes era motivo de discórdia com a igreja católica, na época com poderes temporais associados ao Estado. A condição de "protestante" podia ser convertida em estigma. Até 1889 era preciso autorização legal para a prática religiosa, realizada em casas comuns, sem aparência de templo. A suposta resistência alemã à assimilação não era vista como problema pelo setor imigrantista interessado na colonização que, desde a década de 1840 exigia a liberdade religiosa, o casamento civil e outras providências que pudessem facilitar um fluxo norte-europeu de imigração reivindicações mais tarde repetidas nos textos de Tavares Bastos, Menezes de Souza, Augusto de Carvalho, entre outros. Augusto de Carvalho (1874), um político da província do Rio de Janeiro, menciona os preconceitos contra os estrangeiros particularmente os portugueses e os alemães, coincidentemente os dois fluxos mais significativos de imigrantes na época - usados pela imprensa anti-imigrantista. Nela os alemães são chamados de "raça hostil", protestante em hábitos e índole, antagônica ao Brasil católico e latino. A imigração, nesse caso, aparece antes como processo de invasão de estrangeiros, repulsiva e ameaçadora da singularidade nacional.

O mesmo discurso, centrado na questão assimilacionista, está presente na virada para o século $\mathrm{XX}$, numa forma ainda mais radical, como se observa, por exemplo, em escritos de Silvio Romero, que propõe "conjurar" o germanismo apagando as diferenças culturais que distinguem, no território nacional, as "colônias alemãs". Romero queria a "fusão racial" (miscigenação) e a assimilação cultural processos que considerava imprescindíveis para a formação da nação.

Por outro lado, os imigrantes portugueses, não obstante a herança colonial, base da nacionalidade, também foram alvo de preconceito e xenofobia. A lista de estereótipos varia, mas é a mais óbvia possível na desqualificação, sobretudo quando são mencionados os supostos "defeitos da raça" - indolência, falta de inventividade, grosseria, ineficiência, aversão ao trabalho e assim por diante. Além disso, não representam mais uma das raízes da formação nacional, tornando-se, nessas representações estereotipadas, apenas um grupo de imigrantes inassimiláveis, endogâmicos, ansiosos para enriquecer e retornar a Portugal ${ }^{7}$.

Apesar da sua qualificação latina e católica - características que, supostamente, garantiam a rápida assimilação - os italianos (e, da mesma forma, os poloneses) não escaparam desse tipo de adjetivação negativa. Pode-se dizer que a estereotipia tem relação com as características sociais mais marcantes da maioria dos imigrantes: a condição de colonos (portanto, trabalhador braçal, cultivador do solo) e a pobreza e seus apensos (o analfabetismo e a incultura). A própria legislação, ao definir imigrante como passageiro da $3^{\mathrm{a}}$ classe dos navios estava associando a categoria com a condição social de pobre. Há uma dupla estigmatização na configuração do colono estrangeiro, ao mesmo tempo imprescindível no processo de ocupação territorial e na produção agrícola, portanto, valorizado inclusive por ser "branco europeu", igualmente desprezado pelas elites por seu distanciamento em relação à 
cultura nacional, mas também através da associação com o trabalho na colônia. Eram, sobretudo, os substitutos dos escravos. Além disso, certas formas de categorização do conteúdo preconceituoso, embora situadas na jocosidade, impõem limites sociais: a expressão "linguagem macarrônica" (ou "português macarrônico”), a generalização de categorias como carcamano (que remete à desonestidade) e alemão batata, por exemplo, traduzem com precisão os significados dos estereótipos - tipificam, caricaturalmente, os membros de um grupo.

Roche (1969: 708-709) observou o desprezo e hostilidade dos brasileiros em relação aos colonos alemães, sobretudo com o recrudescimento do nativismo concomitante ao crescimento numérico, à consciência coletiva dos teuto-brasileiros e reivindicações de natureza política das lideranças étnicas. De fato, podem ser identificados vários motivos para a exacerbação dos preconceitos em relação aos imigrantes e descendentes estabelecidos no país, particularmente aqueles que participaram do processo de colonização na região sul. As diferenças culturais e sua expressão simbólica na conformação das identidades étnicas carregada de etnocentrismo eram percebidas como ameaça à formação nacional claramente assimilacionista. Esse confronto entre o princípio da nacionalidade (que exigia o "abrasileiramento") e as etnicidades agravou-se após a Primeira Guerra Mundial, quando houve um endurecimento das leis imigratórias na maioria dos países diante do grande número de refugiados e apátridas deslocados pelo conflito.

As restrições à imigração no Brasil foram ampliadas, até chegar à política de cotas em 1934, por causa dos postulados eugenistas que excluíram doentes, deficientes e, de modo mais subjetivo, os indesejáveis por critérios étnicos ou raciais, e pelo temor de uma abertura a grupos de refugiados e aos indesejáveis por razões ideológicas e políticas. Mas havia o problema interno da assimilação, também levado em conta na discussão das políticas imigratórias. Na prática, a intolerância nacionalista com as diferenças culturais e a incompatibilidade discursiva entre xenofobia e o etnocentrismo identitário dos chamados "alienígenas", ocasionou a implementação da campanha de nacionalização a partir de 1937.0 discurso da nacionalização foi particularmente intenso na produção de preconceitos e na criação de categorias acusatórias. No caso dos alemães, devido à presença pangermanista e nazista, e os dois conflitos mundiais, havia o pressuposto do separatismo e da traição no uso de categorias como boche, quinta-coluna, alemão-de-merda - bastante usadas e de conteúdo generalizador principalmente durante o Estado Novo. Não são categorias presentes apenas nos escritos militares e outros que justificaram a campanha de nacionalização como "imperativo da unidade nacional” (Seyferth, 1982: 175199); eram de uso comum, cotidiano, numa situação em que os brasileiros deviam impor sentimentos patrióticos e a cultura nacional aos alienígenas - um termo que anulava o jus soli em nome da brasilidade para incluir todos os imigrantes e descendentes não assimilados. Excetuando alienígena, as demais categorias ainda são empregadas hoje, com um sentido de distintividade, para destacar comportamentos atribuídos a uma suposta índole coletiva na construção da imagem do alemão "arrogante", "prepotente" e, eventualmente, "inimigo traiçoeiro".

Desde o período mais intensivo da imigração - cujo auge ocorreu na virada para o século XX - os "latinos" (italianos, espanhóis e portugueses) receberam a classificação de "assimiláveis", considerando a suposta "proximidade cultural" com a formação brasileira, mantida na argumentação sobre cotas e política imigratória em geral durante o Estado Novo. Esse qualificador, porém, não foi capaz de atenuar a condenação das diferenças: na visão nacionalista e da própria sociedade continuaram estrangeiros ou filhos de estrangeiros. No cotidiano atual das relações interétnicas no sul, por exemplo, os atributos estereotipados conferidos aos italianos contêm julgamentos da ordem moral briguentos, trapaceiros, carcamanos, bêbados, grosseiros, etc. - supondo sua natureza biológica ou inata ${ }^{8}$. São gringos, um termo qualificador do estrangeiro usado quando alguém quer se distinguir dos descendentes de colonos. Nesse sentido, o Vale do Itajaí - que no Estado Novo foi considerado um território desprovido do "espírito nacional" - ainda é um lugar de gringos para aqueles que as lideranças étnicas da década de 1930 identificavam como "luso-brasileiros".

Certos fatos acirraram os ânimos nacionalistas acerca da questão imigratória no Estado Novo. Em primeiro lugar, havia consenso quanto à necessidade da vinda de imigrantes para o Brasil; em segundo lugar, as medidas nacionalizadoras que vinham sendo preconizadas desde o início da República (Romero, 1902, por exemplo) - entre outras coisas, a imposição da língua portuguesa, a intervenção no ensino particular e nas publicações, e o fechamento das instituições comunitárias - foram levadas à prática, inclusive por tropas do exército e pela polícia política; em terceiro lugar, apesar do descrédito das teses raciais deterministas, ainda vicejavam entre os membros do Conselho de Imigração e Colonização certos pressupostos relativos à mestiçagem ligados ao velho mito do branqueamento. Perdurava a crença de que era possível formar no Brasil um povo fenotipicamente "branco" com o concurso da imigração. Atenuava-se o discurso por eufemismos (como a substituição do termo raça por etnia ou nacionalidade, mantendo o conteúdo biológico) para condenar a imigração japonesa ou judaica (a africana sequer era cogitada) em nome dos caminhos da formação nacional. Assim, os imigrantes necessários deviam ser "rigorosamente selecionados", levando em conta um critério de eugenia racial (entre outros), o que levou a malabarismos retóricos bastante preconceituosos, para excluir fluxos que não fossem oriundos do ocidente europeu. A questão mais evidente nesse momento era a miscigenação em sinonímia com assimilação. $\mathrm{O}$ elemento definidor do imigrante ideal é o que Oliveira Vianna denominou "fusibilidade" - isto é, a raça ou nacionalidade mais propensa a integrar o "melting pot" nacional. Dessa forma, os japoneses, por exemplo, eram duplamente e contraditoriamente estigmatizados: para 
Oliveira Vianna (e muitos outros) eram como enxofre, insolúveis - portanto, não se deixariam assimilar; mas aventada a hipótese da mistura (ou assimilação), não serviam aos princípios desejados da formação nacional por causa das diferenças raciais e da distância cultural ${ }^{9}$. Ao instituir esse formato de categorização do imigrante, o "abrasileiramento" articulado à "mistura racial" e assimilação tornou-se o qualificador essencial da cidadania e nacionalidade. $\mathrm{O}$ conjunto das diferenças culturais trazidas pela imigração estava sendo objeto de xenofobia e suspeição; quando muito, alguns traços culturais eram aceitáveis, sobretudo aqueles que podiam ser acomodados no rótulo do folclore ou dos hábitos alimentares. Mas a pluralidade cultural no seu significado étnico e, especialmente, o uso cotidiano de outra língua feria o princípio da nacionalidade e a unidade da nação. Os princípios de identificação coletiva do nacionalismo e das etnicidades, instruídos por critérios de tipo etnocêntrico, são incompatíveis, principalmente no contexto do Estadonação assimilacionista avesso à pluralidade cultural. No tempo presente os radicalismos nacionalistas que levaram à intervenção, muitas vezes violenta, junto às comunidades imigrantes, particularmente naquelas áreas de maior concentração de gente de uma mesma etnia, estão atenuados. Mas aqueles que vivenciaram a ocupação militar dos espaços comunitários étnicos, como ocorreu no Vale do Itajaí e outras áreas de colonização, mesmo passado meio século, ainda condenam os excessos xenofóbicos da campanha de nacionalização; e os relatos mnemônicos da época ajudam a construir as representações identitárias em contraste com os outros brasileiros.

\section{PREMISSAS ETNOCÊNTRICAS DE IDENTIDADES COLETIVAS}

O principal objetivo da ação nacionalizadora iniciada na década de 1930 era acabar com os "quistos étnicos" formados pela imigração no sul do Brasil: as populações "enquistadas" precisavam ser diluídas, caldeadas, misturadas, digeridas - para citar algumas metáforas usadas para falar dos problemas de assimilação. $\mathrm{O}$ emprego sistemático da palavra "quisto" (oriunda do jargão médico, para designar um "mal" cuja cura é cirúrgica) é denotativo do sentimento de aversão e estranhamento diante da diversidade "alienígena", em atitudes condenatórias das políticas da colonização anteriores a 1930 por propiciarem a concentração de um grande número de estrangeiros numa só região do país. Decerto a concentração não podia ser atribuída aos imigrantes pois o processo colonizador, mesmo no caso das empresas particulares, foi inteiramente controlado pelo Estado. Mas o isolamento inicial dos colonos e a presença quase insignificante de brasileiros na maioria dos assentamentos certamente contribuiu para consolidar particularidades culturais e ideologias étnicas. $\mathrm{Na}$ década de $1930 \mathrm{a}$ assimilação ainda não estava completa, conforme assinalou Willems (1980) - daí a referência nacionalista aos "quistos", antigos núcleos coloniais, alguns em pleno desenvolvimento econômico, demasiadamente diferentes dos padrões luso-brasileiros de cultura e sociedade. Blumenau, a principal "colônia alemã" de Santa Catarina, tornou-se exemplo paradigmático desse "enquistamento". Ali o português era um idioma quase desconhecido, falava-se a língua alemã, a arquitetura, a vida associativa (bastante intensa), os comportamentos eram outros ou, como disse o tenente Rui Alencar Nogueira (1947: 40). "Blumenau apresenta sistemas de vida inteiramente diferentes das outras cidades brasileiras, pelos costumes e usos".

A referência a tais estranhamentos, a crítica muitas vezes preconceituosa dos nacionalizadores às lideranças comunitárias ${ }^{10}$, tem o propósito de assinalar a diversidade cultural produzida pela colonização e fundamento da construção e reconstrução simbólica de identidades étnicas. A idéia de "quisto" é um indicador da dificuldade de harmonizar nacionalismo e identidades cujos enunciados simbólicos apelam ao jus sanguinis e às singularidades das culturas nacionais. $\mathrm{O}$ imigrante, de fato, é um intruso, alguém não reconhecido como integrante do Estado-nação, ou apenas parcialmente reconhecido quando se naturaliza; a atribuição categórica de alienígena se estende aos descendentes no discurso assimilacionista que exige a conformidade com os costumes e a cultura nacional. Por outro lado, o itinerário da imigração serve à construção da identidade de imigrante $\mathrm{e}$, por extensão, da etnicidade. E esse itinerário inclui o processo de ocupação do espaço, a fronteira agrícola colonizada, convertida em símbolo da civilização e do progresso. De fato, os diferentes grupos de imigrantes criaram princípios de pertencimento coletivo evocativos da origem comum nacional e da experiência da colonização. A definição das identidades, portanto, apela às peculiaridades de cada grupo, mas todos compartilharam do mesmo itinerário de transformação do imigrante em colono. Considerando o caráter relacional dessas noções de pertencimento, inclusive na sua dimensão territorial, no mundo da colônia os brasileiros são estranhos, os que estão fora, não pertencem à comunidade, embora sejam o referencial necessário da distintividade.

Conforme foi observado, o modelo de colonização facilitou o estabelecimento de imigrantes de mesma procedência nacional em colônias singulares e, depois, mistas; mas pelo menos na fase de localização em lotes coloniais, não houve participação significativa de brasileiros. Os alemães foram os primeiros protagonistas dessa ocupação e, com a intensificação do fluxo imigratório a partir de 1850 , surgiram as primeiras manifestações de pertencimento étnico e a formalização da identidade teutobrasileira.

O editorial do número piloto do Kolonie Zeitung, um dos mais duradouros jornais em língua alemã do sul, publicado em Joinville (SC) entre 1862 e 1939 (portanto, extinto pela campanha de nacionalização), é um bom exemplo de formalização de uma identidade incompatível com o ideal assimilacionista do nacionalismo brasileiro. Evocando a pátria deixada para trás pelo imigrante, diz o editorialista:

"A fundação deste jornal se deve, 
primordialmente, ao desejo de contribuirmos para que todos os imigrantes alemães que escolheram o Brasil meridional, e principalmente, a Província de Santa Catarina para se estabelecerem, aqui encontrem, realmente, uma nova Pátria, sem que isso implique na perda da sua antiga pátria” (Kolonie Zeitung, 20/12/1862, p. 1).

Aí está implícita a identidade hifenizada, conformada, igualmente, pelo que o editorialista chamou de índole e espírito germânico. Mas o que interessa reter, à parte as outras subjetividades da noção de Deutschtum (germanidade) é o significado de pátria nessa ideologia étnica. $\mathrm{O}$ primeiro fundamento do discurso sobre Heimat (pátria) está na situação de frente de expansão vivida pela primeira geração de imigrantes, por causa da localização das colônias em regiões de acesso precário.

Os problemas enfrentados pelos colonos são bastante conhecidos e descritos na historiografia da colonização; em parte foram causados pelo isolamento e pela falta de recursos para implementação da infra-estrutura necessária aos assentamentos. Na maior parte das colônias fundadas no século XIX os imigrantes enfrentaram epidemias, tiveram que suprir com seu próprio esforço as demandas de serviços públicos (construção de escolas, alojamentos, abertura de caminhos, demarcação das terras, etc), realizaram o trabalho penoso da derrubada e plantio imagem mais freqüentemente acionada nas representações da identidade do colono pioneiro. Esses fatos marcantes dos primórdios da vida colonial deram respaldo ao discurso civilizatório e à elaboração das características determinantes da idéia de Heimat. A longa continuidade do processo colonizador na região sul, e a "enxamagem" evocada por Roche (1969) envolvendo os descendentes de imigrantes face à demanda por novas terras, mantiveram em evidência o "ciclo pioneiro" - isto é, as histórias das conquistas de florestas por pioneiros abnegados e trabalhadores (portanto, a figura do "colono na selva") foram realimentados pela fundação de novas colônias. A colonização deu lugar ao aparecimento de uma classe camponesa de pequenos proprietários, em sua maioria de origem européia, formando, conforme denominação de Waibel (1958: 206) "comunidades próprias". Assim, imigrantes de diversas nacionalidades compartilharam o mesmo processo de povoamento, o mesmo "ciclo pioneiro" em diferentes períodos, mas produziram configurações culturais diversas. A denominação "colônia alemã", por exemplo, dimensiona uma organização comunitária diferenciada, o uso da língua alemã, um ethos de trabalho e um modo de vida vinculados aos ideais de germanidade. Tem em comum com outras colônias adjetivadas - a "italiana" e a "polonesa" - o compartilhamento da colonização, o que as aproxima em muitas características da vida social e econômica, e também na apropriação do pioneirismo, não obstante a reivindicação de precedência dos "alemães".

Colonização, pioneirismo e germanidade são as marcas da identidade teuto-brasileira, e seu símbolo mais recorrente entre os descendentes dos imigrantes, inclusive hoje, é o da conquista da floresta pelo trabalho árduo e eficiente: a colônia emerge como um espaço construído onde a floresta dá lugar à civilização e ao progresso. A figura de retórica predominante é o "trabalho alemão", definido como qualidade herdada, decorrente da origem racial. A partir dela, o progresso das áreas coloniais, desde a derrubada da floresta até o crescimento urbano e industrial dos antigos núcleos coloniais, aparece no discurso étnico como exemplo das virtudes do imigrante alemão. A imagem ideal do pioneiro é a de um sujeito capaz de criar civilização e progresso em condições adversas porque traz a eficácia no sangue. Essa é uma expressão aberta de etnocentrismo, visível na década de 1930 , por exemplo, no contexto dos debates sobre a instituição do "dia do colono", e presente até hoje na exteriorização da identidade teuto-brasileira (ou alemã, como preferem os colonos). Na discussão sobre o "dia do colono" as lideranças teuto-brasileiras envolvidas claramente transformaram os alemães nos "pioneiros" de direito; e o "dia", afinal instituído mais tarde, foi, de fato, o da fundação de São Leopoldo, a primeira das colônias -25 de julho, data até hoje festejada, mas sem os referenciais especificamente germânicos, pois engloba todos os "colonos de origem" (uma expressão vinculada à imigração), excluindo os (luso) brasileiros.

Retomando a questão da Heimat, ou pátria, a colônia aparece nas representações da identidade como um território étnico, construído pelo "trabalho alemão", portanto, mantidas as características própria da tradição, cultura e índole germânicas, torna-se a nova pátria do colono. Essa forma de representação evoca o primordialismo do jus sanguinis e, principalmente, o espaço ou território onde se situa o lar (Heim) - pois Heimat, por seu prefixo, é termo evocativo do lugar onde se vive na forma mais restrita - o lar, a comunidade. A noção de pátria é fundamental na concepção do Estadonação. Assim, o uso da palavra Heimat nessa forma restritiva de territorialização do pertencimento étnico no Brasil afrontou o princípio da nacionalidade, ajudando a criar a imagem contrastante de "quisto" alienígena condenado pelas idealizadores da campanha de nacionalização. Contudo, é preciso assinalar que a idéia de Heimat tem outras ambigüidades pois, embora primeiramente referida à comunidade colonial (em geral), é extensiva ao Brasil enquanto Estado. Não postula a vinculação ao Estado alemão; a Alemanha é a Urheimat (pátria original) e o Brasil a nova pátria, enunciando sentimentos de lealdade e pertencimento político ao país de acolhida. A definição da identidade teuto-brasileira, porém, sugere não só uma reivindicação ao pluralismo cultural mas, igualmente, a pertença a outro povo ou raça, com cultura e costumes próprios.

A última observação aponta para um problema crucial no conflito com o nacionalismo brasileiro da primeira metade do século $\mathrm{XX}$, pois remete a concepções mais radicalizadas da germanidade (Deutschtum). Houve uma longa história de conflitos, incluindo duas guerras mundiais que deixaram a população teutobrasileira na incômoda situação de potencial inimiga, dada a posição do Brasil nos dois conflitos, e a interminável discussão sobre o "perigo alemão" - a 
suposta intenção separativa dos "colonos", com patrocínio da Alemanha, aventada desde a década de 1890. Mas interessa reter aqui a contraposição teuto-brasileira aos pressupostos da assimilação enquanto melting-pot.

Em primeiro lugar, há o critério de superioridade racial às vezes usado para defender a endogamia, particularmente visível em matérias da imprensa teutobrasileira, por exemplo, nos dois períodos de influência de doutrinas racistas, mais precisamente do pangermanismo na virada para o século XX, do nazismo na década de 1930 . O discurso racializado é condenatório da mestiçagem, defendendo a pureza racial germânica a partir do pressuposto preconceituoso da inferioridade dos mestiços e negros que compõem a população brasileira. Até aí, nada muito diferente do racismo encontrado entre notáveis representantes da elite brasileira que pretendiam o branqueamento do país através do "caldeamento" com imigrantes europeus, exatamente porque acreditavam na desigualdade racial. Mas junto com a condenação da mestiçagem, alguns escritos teuto-brasileiros ridicularizaram o ideal de branqueamento. Resumindo, no embate entre dois racismos conflitantes, defendese a especificidade étnica das "colônias alemãs" como um "direito", já que o Brasil é um Estado racial e culturalmente plural ${ }^{12}$.

Em segundo lugar, deve-se considerar as diferenças culturais que singularizam aquilo que todos chamam de "colônia alemã", especificidades apontadas inclusive na obra de E. Willems dedicada à assimilação (social). Diferenças acionadas para marcar a identidade coletiva, a especificidade em relação aos outros colonos e aos brasileiros. Deutschtum tem um significado cultural apreendido do pensamento nacionalista alemão, e assume a língua, os costumes, enfim, a Kultur como marcas diferenciadoras; além, obviamente, do conteúdo racial implícito na idéia de "sangue comum". Sendo assim, há o pressuposto de uma superioridade cultural - a noção de Kultur tem sentido civilizatório - particularmente enfatizada no período anterior à campanha de nacionalização; e mais subjetivamente acionada hoje, no cotidiano. Algumas marcas diferenciadoras são, inclusive, assinaladas em comemorações e festas periódicas associadas à imigração, sobretudo nas últimas décadas caracterizadas pela reelaboração da identidade cultural cheia de referências à língua alemã, hábitos alimentares, estilos de vida, limpeza (no sentido higiênico do termo), e o velho "trabalho alemão" associado à colonização.

No discurso etnocêntrico de senso comum, atual e passado, estereótipos e preconceitos servem para estabelecer distinções hierarquizadas entre descendentes de imigrantes e os brasileiros representados pela categoria caboclo em oposição aos colonos. Embora não pareça, é uma distinção que pressupõe inferioridade racial, pois os estigmas da ineficiência e da preguiça são associados ao "sangue", ao tipo físico. Os termos empregados, por seu caráter estereotipado, são bastante significativos: atrasado, preguiçoso, cachaceiro, sem raízes (ou nômade), malandro, etc. A distinção é simplesmente categórica: os alemães (ou colonos) têm origem, os brasileiros (caboclos) não. Origem, nesse caso, é uma referência à imigração, mas também possui conteúdo racial.

As mesmas formas de diferenciação são encontradas nos outros grupos de imigrantes, seja na configuração de uma identidade étnica frente à sociedade nacional, seja na apropriação dos valores da colonização. Não é possível fazer uma comparação mais geral nos limites de um artigo, mas algumas referências à italianidade (Italianitá) têm utilidade para mostrar que a experiência da colonização - portanto, a sociedade e o sistema cultural formados em solo brasileiro - não é exclusiva das representações da etnicidade teuto-brasileira. Thales de Azevedo (1982) associou o movimento pela italianidade no Rio Grande do sul a um esforço do grupo étnico para proteger-se da perda de sua cultura e lealdade em relação à pátria de origem. Daí a importância assumida pela língua italiana (apesar dos vários dialetos), pelas associações, agremiações de auxílio mútuo, pela "escola italiana”, etc. Tratavase, segundo este autor, da "defesa da herança cultural que se procura compatibilizar com a lealdade à pátria adotiva" (Azevedo, 1982: 259).

Não existe algo semelhante à noção de Heimat na elaboração dessa identidade italiana. Mas os sinais da italianidade também estão contidos na idéia da língua comum (o talian, termo designativo da fala italiana no Rio Grande do sul), e outros aspectos significativos da cultura relacionados à organização familiar, à religião católica, hábitos alimentares, enfim, aqueles elementos que integram os "costumes" (Oro, 1996; Zanini, 2000). Além disso, também está presente no discurso étnico a idéia do território - a "colônia italiana" como um lugar diferente e melhor, construído pelo trabalho civilizador do imigrante. Assim, a colonização serve de base à construção do imigrante eficiente, o colono herói civilizador, pioneiro, conforme observaram Zanini (2000) e Santos (2004), numa concepção valorativa do ethos de trabalho, marcada pela idéia de desbravamento e ocupação de espaços vazios, muito próxima da versão teutobrasileira sobre o "colono alemão". Também reivindica-se o pioneirismo civilizador, glorifica-se o colono construtor do progresso - verdadeiro herói cultural numa atualização permanente da identidade étnica até o presente. Na autoimagem, o colono italiano é valorizado pela operosidade, capacidade de trabalho e de acumulação, sobriedade, perseverança e muitas outras "virtudes", em oposição aos brasileiros desqualificados pelas categorias "negrada" e "pelo duro", dois termos de inequívoco conteúdo racial, apesar de não estarem referidos à cor da pele. Trata-se, segundo Zanini (2000) de termos que designam gente considerada de menos valia, que não possui ascendência européia, preguiçosos e pouco religiosos. A classificação estereotipada dos brasileiros, paradoxalmente, é acompanhada da valorização da identidade gaúcha, presente, inclusive, na categoria hifenizada ítalo-gaúcho em iugar de ítalo-brasileiro. Por outro lado, no contexto interétnico existe a percepção negativa dos colonos italianos pelos brasileiros e, eventualmente, por colonos de outras "origens". Nas representações de brasileiros, são gringos rudes, grossos, sovinas (pão-duros), 
briguentos, enganadores (carcamanos) formas preconceituosas radicalizadas durante a campanha de nacionalização, que também reprimiu a italianidade, interferindo nas instituições comunitárias e no domínio doméstico, tal como ocorreu nas "colônias alemãs". Essa alteridade que marca as distinções étnicas, atualizadas por eventos como a Festa da Uva, mantém a italianidade como um valor primordial, associado ao "sangue comum" (Zanini, 2000) e destaca a imagem mítica do pioneiro que venceu a selva trazendo o progresso. A análise empreendida por Santos (2004) sobre a festa da uva (realizada em Caxias do Sul), com destaque também para a simbologia da colonização contida na iconografia e nos monumentos ao imigrante, mostra que uma festa urbana, organizada por membros da classe alta (industriais, intelectuais), atualiza, a cada dois anos, a auto-imagem coletiva que remete ao pioneiro. Assim, um amplo painel do pintor Aldo Locatelli inclui desde a derrubada da mata, no início da colonização, até a grande indústria caxiense, passando pela vindima, a atividade artesanal - glorificando o trabalho familiar; os índios estão ocultos na folhagem, meros observadores no relato do progresso, do fazer a América, também contado nos desfiles alegóricos realizados durante as festividades.

Finalmente, o compartilhamento do mesmo processo de ocupação territorial e da mesma categoria social - coleno - não esmaeceu as diferenças culturais apropriadas na construção das identidades étnicas, nem tampouco as formas estereotipadas e às vezes preconceituosas de marcar a distintividade. Os descendentes de poloneses, por exemplo, são designados por uma categoria pejorativa - polaco - e considerados pelos outros descendentes de imigrantes "falsos, pouco inteligentes, atrasados"; e replicam chamando os "alemães" de "arrogantes" e os "italianos" de "pão-duros, desonestos, gananciosos", estes, por sua vez, falam de "alemães perdulários" e excessivamente crentes da sua superioridade. São traços, sobretudo vinculados ao caráter e honra étnicos, usados para tipificar comportamentos, representações estereotipadas que revelam o etnocentrismo de cada grupo, embora ninguém conteste a igualdade e legitimidade contidas na idéia de colonização como um processo compartilhado de progresso e civilização do qual o brasileiro (caboclo, pelo duro, etc) é excluído.

\section{CONSIDERAÇÕES FINAIS}

As breves referências às manifestações acerca das identidades coletivas surgidas no contexto imigratório da colonização no sul do Brasil mostram a constância dos preconceitos (no sentido corriqueiro de prejulgamento sem fundamento) e estereótipos na conformação das diferenças culturais demarcadoras das fronteiras simbólicas de cada grupo, embora compartilhem da apropriação de uma mesma categoria social - colono que une todos em oposição aos brasileiros. Cada grupo conta a mesma epopéia do herói civilizador - tema particularmente enfatizado por "italianos" e "alemães" representando a conquista de um território selvagem e perigoso. Define-se o colono por referência a uma "origem" nacional européia que, por princípios etnocêntricos, exclui os brasileiros designados por categorias denotadoras de pressupostos de inferioridade cultural e racial, apesar do pouco uso de referências explícitas ao fenótipo. A exclusão não está presente apenas nos discursos étnicos daqueles que se apropriaram da vinculação entre colono e progresso, pois foram prejulgamentos racistas que embasaram o cerceamento da entrada de nacionais em áreas de colonização, professados pelas elites imigrantistas que acreditavam na superioridade do branco europeu.

O contato entre descendentes de imigrantes e os brasileiros tornou-se mais significativo na década de 1930 , diante do crescimento econômico de algumas excolônias, período também marcado pela campanha de nacionalização. $\mathrm{O}$ contato $\mathrm{e}$ o propósito de assimilação à força que norteou a ação nacionalizadora, por sua vez, produziram um discurso xenofóbico em torno da categoria alienígena, igualmente estereotipado e preconceituoso, pontuado por termos denotativos de traição e ausência de patriotismo.

Finalmente, apesar do uso de expressões aparentemente jocosas ou inconseqüentes na categorização dos outros, elas contêm julgamentos de valor que apontam para dispositivos preconceituosos e para as dificuldades de aceitação das diferenças culturais que podem ou não resultar em discriminação. As subjetividades próprias dos etnocentrismos interferem nas relações sociais. Não há nada de neutro ou ingênuo nas concepções estereotipadas que servem para desqualificar os outros, os diferentes, aqueles que não pertencem ao grupo, não compartilham da mesma identidade.

* Giralda Seyferth é Prof ${ }^{a}$ do Dpto. de Antropologia / Museu Nacional-UFRJ.

\section{NOTAS}

1 - Não há registro confiável do número de imigrantes localizados em núcleos coloniais no periodo de 1824 a 1830; as estimativas oscilam entre quatro e seis mil indivíduos (Willems, 1980: 40). A interrupção do processo teve duas causas: o decreto legislativo que proibiu despesas com a imigração, promulgado em 1830, e a guerra civil (Revolução Farroupilhas), iniciada em 1835 e encerrada em 1845.

2 - Sobre as formas de exclusão, e a "questão racial", ver Seyferth, 2002a.

3 - O Michaelis/Moderno Dicionário da Lingua Portuguesa é mais preciso, apresentando uma definição sociológica do termo estereótipo na página 893: "imagem mental padronizada, tida coletivamente por um grupo, refletindo uma opinião demasiadamente simplificada, atitude afetiva ou juizo incriterioso a respeito de uma situação, acontecimento, pessoa, raça, classe ou grupo social".

4 - É preciso observar que a maioria dos autores assinala que tanto preconceitos como estereútipos podem ser negativos, positivos e contraditórios. Sobre isso, ver Adorno e colaboradores (1969), Preiswerk e Perrot (1975).

5 - O termo Folkways foi criado por Sumner para indicar os hábitos e costumes que caracterizam um grupo. Além do conceito de etnocentrismo, introduziu nas ciências sociais os termos in-group - grupo cujos membros possuem um senso de 
solidariedade e comunidade por compartilhar os mesmos folkways - (em contraste com) out-group, grupo que possui folkways diferentes e muitas vezes é objeto de aversão e hostilidade. A obra de Sumner é marcadamente evolucionista, mas estes termos foram amplamente utilizados nos estudos étnicos.

6 - Na República a política imigratória continuou no âmbito da pasta da Agricultura - parte do Ministério da Agricultura, Indústria e Comércio (MAIC) - e a colonização (e, conseqüentemente, a imigração ficou na alçada do Serviço de Povoamento do Solo Nacional criado em 1907. Os dois autores em questão foram, pois, funcionários do mesmo ministério e produziram relatórios que deviam instruir a política de imigração e colonização.

7 - Sobre estas representações acerca da imigração alemã e portuguesa, ver Seyferth, $2002 b$.

8 - Essa forma de categorização é comum no Vale do Itajaí; Zanini (2000) também a observou numa região colonial italiana do Rio Grande do Sul.

9 - Sobre esta retórica racista vigente na discussão da imigração, ver Seyferth, 2002a.

10 - As lideranças locais, principalmente religiosas e políticas, e as mães, pelo papel de educadoras dos filhos, foram acusadas de fomentar sentimentos anti-patrióticos e lealdades espúrias ou, numa outra metáfora médica corriqueira nos discursos dos nacionalizadores, espalhavam o "vírus da desnacionalização" (Seyferth, 1997).

11 - Sobre essa questão, ver Gertz (1991).

12 - A familiaridade das lideranças teutobrasileiras com a tese do branqueamento é concomitante com suas primeiras elaborações na década de 1880 (Seyfert, 2002b).

\section{REFERÊNCIAS BIBLIOGRÁFICAS}

ALPORT, Gordon W.

(1958) The nature of prejudice. Nova York, Anchor Books.

AZEVEDO, Thales de

(1982) Italianos e gaúchos. Rio de Janeiro, Cátedra, Brasília, INL.

CARVALHO, Augusto de

(1874) Estudo sobre a colonização $e$ emigração para o Brazil. Lisboa, Tipografia do Comércio do Porto.
ERIKSEN, Thomas $\mathrm{H}$. (1993) Ethnicity \& Nationalism. Anthropological perspectives. Londres, Pluto Press.

GERTZ, René

(1991) O perigo alemão. Porto Alegre, Ed. Universidade (UFRGS).

HARDING, John

(1972) "Stereotypes". In: International Encyclopedia of the Social Sciences, 15. Nova York, Macmillan, pp. 259-261.

KLINEBERG, Otto

(1972) "Prejudice I. The Concept". In: International Encyclopedia of the Social Sciences, 12. Nova York, Macmillan, pp. 439-449.

LEVI-STRAUSS, Claude

(1970) "Raça e história". In: Raça e Ciência I (UNESCO). São Paulo, Perspectiva.

LEVINSON, Daniel J.

(1969) "The study of ethnocentric ideology". In: Adorno, T. W. et all. The authoritarian personality. Nova York, Norton,

MENEZES E SOUZA, J. C. de (1875) Theses sobre a colonização do Brazil. Rio de Janeiro, Tipografia Nacional.

NOGUEIRA, Rui A. (1947) A nacionalização do Vale do Itajaí. Rio de Janeiro, Ministério do Exército.

\section{ORO, Ari P}

(1996) "Mi so talian: considerações sobre a identidade étnica dos descendentes de italianos do Rio Grande do Sul". In: BONI, Luis A. de (org.) A presença italiana no Brasil. V.III. Porto Alegre, EST.

PREISWERK, Roy e PERROT, Dominique (1975) Ethnocentrisme et Histoire. Paris, Anthropos.

ROCHA, Joaquim da Silva (1918) História da colonização do Brasil. Rio de Janeiro, Imprensa Nacional.

ROCHE, Jean

(1969) A colonização alemã e o Rio Grande do Sul. Porto Alegre, Ed. Globo.

ROMERO, Silvio

(1902) O elemento português no Brasil. Lisboa, Tipografia da Cia. Ed. Nacional.

SANTOS, Miriam de O.

(2004) Bendito é o fruto: festa da uva e identidade entre os descendentes de imigrantes italianos de Caxias do Sul RS. Tese de Doutorado, PPGAS-Museu Nacional-UFRJ.

SEYFERTH, Giralda
(1982) Nacionalismo e identidade étnica. Florianópolis, Fundação Catarinense de Cultura.

SEYFERTH, Giralda

(1997) "A assimilação dos imigrantes como questão nacional". In: Mana. Estudos de Antropologia Social (Rio de Janeiro), v. 3(1), pp. 95-131.

SEYFERTH, Giralda

(1999) "Colonização e conflito: estudo sobre "motins" e "desordens" numa região colonial de Santa Catarina no século XIX". In: SANTOS, J. V. Tavares dos (org.) Violência em tempo de globalização. São Paulo, Hucitec.

SEYFERTH, Giralda

(2002a) "Colonização, imigração e a questão racial no Brasil". In: Revista da USP, 53, pp.: 117-149.

\section{SEYFERTH, Giralda}

(2002b) "A singularidade germânica e o nacionalismo brasileiro: ambigüidade e alotropia na idéia de nação". In: BASTOS, Cristiana; VALE DE ALMEIDA, Miguel e FELDMANBIANCO, Bela (orgs.) Trânsitos Coloniais: diálogos críticos lusobrasileiros. Lisboa, Imprensa de Ciências Sociais.

SIMPSON, G. E. e YINGER, J. M.

(1965) Racial and Cultural minorities. $3^{\text {a }}$ Ed. Nova York, Harper.

TAVARES BASTOS, A. C.

(1976) Os males do presente e as esperanças do futuro. $2^{\mathrm{a}}$ ed. São Paulo, Cia. Ed. Nacional; Brasília, INL.

WAGLEY, Charles e HARRIS, Marvin.

(1958) Minorities in the New World. Nova York, Columbia University Press.

WAIBEL, Leo

(1958) Capítulos de Geografia Tropical e do Brasil. $2^{\mathrm{a}}$ ed. Rio de Janeiro, IBGE.

WEBER, Max

(1991) Economia e Sociedade. Brasilia, Editora UnB.

WILLEMS, Emílio

(1980) $A$ aculturação dos alemães no Brasil. $2^{\mathbf{a}}$ ed. São Paulo, Cia. Editora Nacional, Brasília, INL.

WIRTH, Louis

(1945) "The problema of minority groups". In: LINTON, R. (ed.) The Science of Man in the World Crisis. Nova York, Columbia University Press.

ZANINI, Maria Catarina C.

(2000) Italianidade no Brasil Meridional: a construção de identidade étnica na regiāo de Santa Maria (RS). Tese de Doutorado, PPGAS/USP. 